\title{
Die Unterschrift unter dem Vertrag zwischen Byzanz und Venedig aus dem Jahr 1342
}

Am 19. November des Jahres 1341, etwas mehr als fünf Monate nach dem Tod seines Vaters Andronikos' III., wurde der kleine Ioannes V. in aller Eile vom Patriarchen von Konstantinopel zum Kaiser gekrönt ${ }^{1}$. Eines der ersten im Original erhaltenen Dokumente, die in der Folgezeit die kaiserliche Kanzlei verließen, ist der Vertrag zwischen dem Oströmischen Reich und der Seerepublik Venedig aus den letzten Märztagen des Jahres 1342 (Dölger-Wirth, Regesten 2876) ${ }^{2}$ - ein diplomatisches Unicum: Gegen jegliche Usancen des kaiserlichen Urkundenwesens ist der Vertrag nicht mit der roten Namensunterschrift des byzantinischen Kaisers versehen, sondern mit einem (gleichfalls roten) Menologem.

Auf diesen urkundlichen Einzelfall hingewiesen zu haben, ist Franz Dölgers Verdienst ebenso wie die wissenschaftliche Aufarbeitung der Vertragsurkunde und ihrer Unterschrift im Rahmen der Diplomatik, welche so gut wie ausschließlich von ihm alleine getragen wurde. Das unerwartete Menologem beschäftigte ihn dabei über Jahrzehnte hinweg immer wieder ${ }^{3}$. Die zentrale Frage, die sich stellte, war, weshalb man im vorliegenden Fall von der namentlichen Unterzeichnung durch den Kaiser Abstand genommen hatte. Darüber hinaus galt es zu klären, ob die rote Menologemunterschrift, welche der Vertrag aufweist, tatsächlich von der Hand des Kaisers selbst gesetzt worden war. Dies erscheint nicht a priori als selbstverständlich, war doch Ioannes V. Palaiologos zum Zeitpunkt des Vertragsabschlusses erst neun Jahre alt ${ }^{4}$.

1 Zum Datum der Krönung: Nikephoros Gregoras, Rhomäische Geschichte/Historia Rhomaïke. Übersetzt und erläutert von J.-L. van DiETEN, 3. Teil (Kapitel XII-XVII) (Bibliothek der griech. Literatur 24). Stuttgart 1988, 269, A. 103 (Diskussion der griechischen Quellenstellen); zum politischen Hintergrund: D. M. NICOL, The Last Centuries of Byzantium, 1261-1453. Cambridge ${ }^{2} 1993,185$ ff.; DERS., The Reluctant Emperor. A Biography of John Cantacuzene, Byzantine Emperor and Monk, c. 1295-1383. Cambridge 1996, $45 \mathrm{ff}$., bes. $60 \mathrm{f}$.

2 F. DöLGER, Regesten der Kaiserurkunden des Oströmischen Reiches von 5651453, 5. Teil (Schluß): Regesten von 1341-1453, unter verantwortlicher Mitarbeit von P. Wirth. München - Berlin 1965. - Editionen: griech. Text bei F. MikLosich-I. MüLleR, Acta et diplomata (...) III. Wien 1865, 111-114 (Nr. 26); latein. Text in G. M. Thomas-R. Predeldi, Diplomatarium Veneto-Levantinum (...) I. Venedig 1880, 257-259 (Nr. 132); F. DöLGER, Facsimiles byzantinischer Kaiserurkunden. München 1931, 17-18 (Nr. 11) mit Edition der Schlußpassage (griech. und lat.).

${ }^{3}$ Im Jahre 1964 widmete Dölger der Urkunde eine eigene kleine Akademieabhandlung: F. DöLGER, Zur Unterfertigung byzantinischer Chrysobulloi Logoi (Sitzungsberichte BAdW, phil.-hist. Kl., Jg. 1964, Heft 10). München 1964. - Der Titel ist leicht irreführend, da sich die neun Druckseiten umfassende Studie ausschließlich mit dem Vertrag von 1342 und der Frage nach dem Urheber der Unterschrift auseinandersetzt.

4 Als Geburtsdatum Ioannes' V. überliefert Nikephoros Gregoras, Historia X, 3 (Nicephori Gregorae Byzantina historia [...] cura L. ScHopen [Corpus Scriptorum Historiae Byzantinae XIX], 2 Bde., Bonn 1829/1830, hier I 482, 1-3) den 18. Juni 1332. Dieses Datum wird durch eine byzantinische Kleinchronik bestätigt: P. ScHREINER, Die byzantinischen Kleinchroniken, 1. Teil: Einleitung und Text (Corpus Fontium Historiae Byzan- 
Sollte die Unterschrift aber nicht von der Hand des jungen Kaisers stammen, galt es zu klären, welche anderen Personen für eine (stellvertretende) Unterzeichnung in Frage kamen.

Zu den angesprochenen Fragen hatte sich Dölger erstmals bereits 1931 geäußert. Damals nahm er den Vertrag in seine Sammlung der „Facsimiles byzantinischer Kaiserurkunden" auf, wo er ihn eingehend beschrieb und die abschließenden Textpassagen edierte ${ }^{5}$. Zur Unterzeichnung merkte er an, daß von ihr „im Text festgestellt (werde), der Kaiser habe sie mit eigener Hand vollzogen. Wir werden das glauben dürfen, so sehr die Schrift des elfjährigen Knaben Johannes (er war im April 1342 noch nicht 11 Jahre alt [sic]; $[\ldots])^{6}$ durch ihre Sicherheit und Zügigkeit in Erstaunen versetzt "

Betrachtet man den Schriftduktus des Menologems, das der neunjährige Ioannes V. dermaßen sicher unter das Schriftstück gesetzt haben soll, so erstaunt dessen Flüssigkeit und Gewandtheit tatsächlich (Abb. 1 und 3). Dölger freilich sah keine andere Möglichkeit, als das Menologem dem kleinen Ioannes zuzuordnen. Andere Zuweisungsversuche, die er ebenfalls bei der Beschreibung der Urkunde in den „Facsimiles“ referiert, hätten sich als wenig plausibel erwiesen. So bestehe zwar theoretisch die Möglichkeit, daß das Menologem von der Hand des Ioannes Kantakuzenos ${ }^{8}$ stamme, doch habe sich dieser zur Zeit des Vertragsabschlusses nicht in Konstantinopel aufgehalten; es sei aber im Urkundentext ausdrücklich vermerkt, daß der Vertrag im Kaiserpalast ausgestellt worden sei $^{9}$. Eine Unterfertigung durch den Patriarchen Ioannes XIV. Kalekas erscheine „durchaus unwahrscheinlich“, und an eine Unterzeichnung durch die Kaiserinmutter Anna sei ebenfalls nicht zu glauben: „Bei der Einstellung der späteren Byzantiner zu den staatsrechtlichen Befugnissen der kaiserlichen Frauen“, meinte Dölger, sei es „,von vorneherein höchst unwahrscheinlich, daß sie eine so wichtige Handlung auch nur vertretungsweise vornehmen konnten"10.

$\mathrm{Zu}$ guter Letzt schloß Dölger für den vorliegenden Fall auch noch eine Übertragung des Menologemrechtes an eine dritte Person aus. Dergleichen

tinae XII/1). Wien 1975, 102 (Chronik 10, 3). Eine Chroniknotiz im Cod. Bonon. 3632, fol. 352r (Chronik 9, 9 = I 92 SchreINER) gibt den Tag der Geburt etwas kryptisch mit

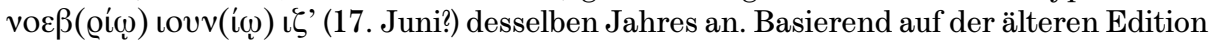

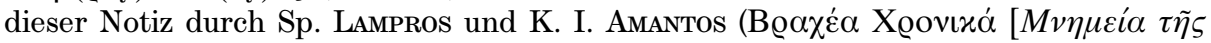

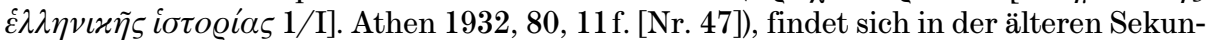
därliteratur gewöhnlich „November 1331“ als Geburtsdatum Ioannes' V. (so beispielsweise bei P. Charanis, An Important Short Chronicle of the Fourteenth Century. Byzantion 13 [1938] 335-362, hier 344, und noch bei G. OsTRoGorsky, Geschichte des byzantinischen Staates. München ${ }^{3} 1963,420$ A. 1). Eindeutig gesichert wurde der 18. Juni 1332 als Geburtsdatum Ioannes' V. durch verschiedene Studien von R.-J. LoENERTZ; s. z. B. La chronique brève de 1352. Texte, traduction et commentaire. Deuxième Partie: de 1328 à 1341. Orientalia Christiana Periodica 30 (1964) 64; Ordre et désordre dans les mémoires de Jean Cantacuzène. Revue des Études Byzantines 22 (1964) 229. DöLGER, Unterfertigung (wie in A. 3) 5, A. 7, geht unter Berufung auf Gregoras korrekt vom 18. Juni 1332 als Tag der Geburt aus. Bei Nikephoros Gregoras, Rhomäische Geschichte/Historia Rhomaïke. Übersetzt und erläutert von J.-L. van DiETEN, 2. Teil, 2. Halbbd. (Kapitel VIII-XI) (Bibliothek der griech. Literatur 9). Stuttgart 1979, findet sich auf S. 335, A. 366, bei der Besprechung des Geburtsdatums versehentlich der 18. Juli 1332.

5 Dölger, Facsimiles (wie in A. 2) 16-18 (Nr. 11); Facsimile des Schlußteils der Urkunde auf Tafel VI (Nr. 11).

6 Zum Geburtsdatum Ioannes' V. siehe oben, A. 4.

7 DöLGER, Facsimiles (wie in A. 2) 16.

$8 \mathrm{Zu}$ seiner Person siehe unten, S. 95.

9 Dölger, Facsimiles (wie in A. 2) 16.

10 Dölger, a. $\mathrm{O}$. 
sei zwar während der byzantinischen Epoche einige Male vorgekommen, doch werde stets der Ausnahmecharakter solchen Handelns betont. Überdies sei „zur Zeit der Unterzeichnung im Jahre 1342 niemand vorhanden (gewesen), von dem anzunehmen wäre, daß er im Kaiserpalast den Vertrag mit Venedig unterzeichnet hätte, als der jugendliche Johannes V."11. Bemerkungen über charakteristische Eigenschaften im Schriftduktus des Menologems unter dem Vertrag von 1342, die, verglichen mit späteren Menologemunterfertigungen Ioannes' V., ebenfalls für dessen autographen Charakter sprächen, schließen Dölgers Beweisgang ab. „Hatte der junge Kaiser“, so fragte sich Dölger auf der Suche nach einer Begründung für die unerwartete Menolgemunterschrift, „zwar schon die Gewandtheit, um sicher und würdig mit den wenigen Buchstaben des Menologems, nicht aber, um mit der langen Namensunterschrift zu signieren?"12.

Kritik an Dölgers Zuweisung der Unterschrift blieb nicht aus. Antonios Sigalas, selbst gut ausgewiesen auf dem Gebiet der griechischen Paläographie, entgegnete, ihm schienen die von Dölger beigebrachten Gründe, die für eine eigenhändige Unterschrift sprechen sollten, etwas ausgefallen («ỏ $\lambda$ íjov

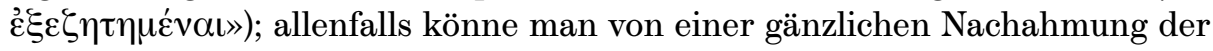
Unterschrift Andronikos' III. in Form einer schematisierten Unterschrift sprechen $^{13}$. Dölger hingegen beharrte während der folgenden Jahrzehnte auf dem von ihm bezogenen Standpunkt ${ }^{14}$. Noch in der Akademieschrift des Jahres 1964 lautete sein Résumé ad subscriptionem: „Es dürfte also feststehen, daß (...) der Vertrag (...) durch Johannes V. mit Menologem beglaubigt worden ist"15. Umso mehr überrascht es, wenn Dölger ein Jahr später in der Einleitung zu seinem fünften Band der Regesten der byzantinischen Kaiserurkunden von dieser Ansicht abrückt und schreibt, es sei ihm „heute wahrscheinlicher, daß das zügige Menologem unter der Urkunde vom 25. März 1342 von dem Megas Logothetes Johannes Raul stammt"16 . - Dies ist bis heute die Lage der Dinge. Sie läßt es gerechtfertigt erscheinen, die Frage nach dem Urheber der Unterschrift unter dem Vertrag des Jahres 1342 noch einmal anzugehen.

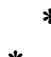

11 DöLger, Facsimiles (wie in A. 2) 17.

12 DölgER, a. O.

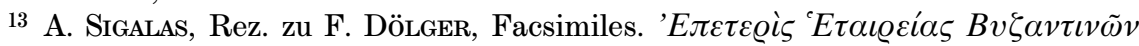
$\Sigma \pi \circ v \delta \tilde{\omega} v 8$ (1931) 364-372, dort 370. Auf den Hinweis SigaLAs', in dem Menologem Ioannes' V. sehe man besser eine Nachahmung des Menologems Andronikos' III., entgegnete DöLGER in dem Aufsatz „Epikritisches zu den Facsimiles byzantinischer Kaiserurkunden“. Archiv für Diplomatik 13 (1933) 45-68 (= DERS., Byzantinische Diplomatik. 20 Aufsätze zum Urkundenwesen der Byzantiner. Ettal 1956, 75-101), dort S. 65 (97). Recht kurz heißt es dort: „Wenn auch im allgemeinen gut zu beobachten ist, wie sich die Form des Menologems des Nachfolgers immer stark an die des Vorgängers anlehnt (eine sehr natürliche Erscheinung), so treten doch die Unterschiede zweifelsfrei bei einer eingehenden Vergleichung ebenso klar zutage“. Eine solche eingehende „Vergleichung“ bringt Dölger jedoch nicht.

${ }_{14}$ Siehe diesbezüglich etwa F. Dölger, Zum Kaisertum der Anna von Savoyen. Erweiterte Besprechung von T. Bertelè, Monete e sigilli di Anna di Savoia, imperatrice di Bisanzio (Byzantinische Zeitschrift 38 [1938] 193-196), in: DERS., ПАРА $П$ ПРА. 30 Aufsätze zur Geschichte, Kultur und Sprache des byzantinischen Reiches. Ettal 1961, 208-221, dort 221.

15 DöLGER, Unterfertigung (wie in A. 3) 9.

16 Dölger-Wirth, Regesten (wie in A. 2) VII. 
Von Inhalt und Vorgeschichte her gesehen stellt der Vertrag des Jahres 1342 zwischen Byzanz und Venedig nichts Außergewöhnliches dar ${ }^{17}$. Nach Verhandlungen mit dem venezianischen Abgesandten Pietro da Canali (entsandt am 17. Juli 1341) werden durch den vorliegenden Vertragsabschluß die Bestimmungen früherer Verträge, insbesondere diejenigen des Vertrages vom November $1332^{18}$, auf weitere sieben Jahre erneuert und modifiziert. Zum Ausgleich von Schäden, die den Venezianern von Reichsangehörigen erwuchsen, erhält Venedig 19.000 Hyperpern in vollgewichtiger Münze, von denen 4.000 sofort, die restlichen 15.000 in fünf gleichen Jahresraten zu begleichen sind. Ferner werden dem venezianischen Gesandten sofort 600 Gulden $(\varphi \lambda \omega \dot{\varrho} \iota \alpha)$ für Nicolò Pisano aus Venedig ausbezahlt, welche die kaiserlichen Beamten in Arta von den Leuten des Pisano erhalten haben. Mit dieser Zahlung sind die Forderungen der Venezianer aus den früheren Verträgen ausgeglichen, unbeschadet der Ansprüche, die seit der Gesandtschaft des Giovanni Gradenigo vom März 1340 entstanden sind. Der Kaiser hingegen verzichtet auf alle Schadensersatzansprüche aus dem Vertrag bis zum 25. März 1342.

Noch heute liegt die Vertragsurkunde, um die es hier geht, außerordentlich gut erhalten im Staatsarchiv von Venedig ${ }^{19}$. Auf starkem Pergament von $57 \mathrm{~cm}$ Länge und $62 \mathrm{~cm}$ Breite steht in schwarzer Tinte links der griechische (Abb. 1), rechts der lateinische Urkundentext (Abb. 2). Direkt unter den griechischen Textblock ist in roter Tinte, wie für kaiserliche Unterzeichnungen üblich, das Menologem gesetzt. Auf der anderen Seite, unter dem lateinischen Textblock, findet sich das Notarszeichen des Andreas de Firmo angebracht, daneben sein Vermerk zur Ausfertigung der Urkunde ${ }^{20}$. Die Goldbulle der Urkunde ist verschwunden; vorhanden sind noch die fünf zum Durchzug der Fäden eingestochenen Löcher im unteren Teil der Urkunde sowie Reste violetter Seidenfäden, mit denen einstmals das Siegel befestigt $\operatorname{war}^{21}$.

Wendet man sich dem Menologem unter dem Vertragstext zu, so fällt zu-

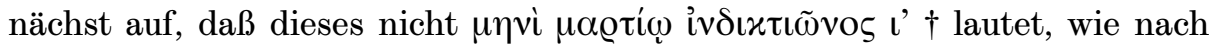
den Datierungselementen im Eschatokoll (25. März 1342) ${ }^{22}$ zu erwarten

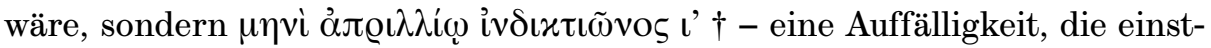
weilen beiseite gelassen sei. Wie erwähnt, untersuchte Dölger das Menolo-

17 Die folgende Darstellung des Inhalts nach den präzisen Ausführungen bei DöLGER-WIRTH, Regesten (wie in A. 2) 2876; vgl. ferner D. M. NiCoL, Byzantium and Venice. A Study in Dipolmatic and Cultural Relations. Cambridge 1988, 258f.

18 F. DöLGER, Regesten der Kaiserurkunden des Oströmischen Reiches von 5651453, 4. Teil: Regesten von 1282-1341. München - Berlin 1960, 2787; vgl. auch NicoL, Byzantium and Venice (wie in A. 17) 255.

19 Archivio di Stato Venezia, Miscellanea, atti, diplomi e privilegi. Ind. cron. sec. VIII-XIII, n. 480.

20 (S. N.) Ego Andreas de Firmo imperiali auctoritate notarius et ducatus Veneciarum scriba predictis omnibus interfui et ea de voluntate tam dicti domini imperatoris quam dicti ambaxatoris scripsi et in publicam formam redegi. (DöLGER, Facsimiles [wie in A. 2] 17 f., Z. 12-14).

${ }^{21}$ Zur diplomatischen Beschreibung des Stücks siehe DöLGER, Facsimiles (wie in A. 2) $16 \mathrm{f}$., und DöLGER-WIRTH, Regesten (wie in A. 2) 2876.

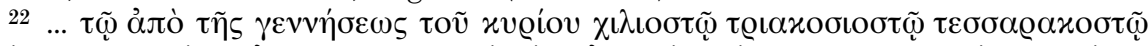

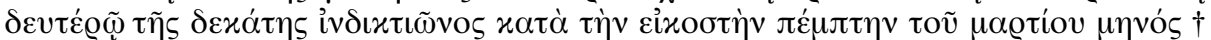
bzw. in der lateinischen Übersetzung: Anno a nativitate domini millesimo trecentesimo quadragesimo secundo, indictione decima, die vigesimoquinto mensis marcii (DöLGER,

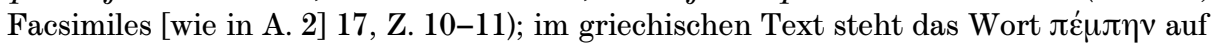
Rasur (vgl. DöLGER, Facsimiles [wie in A. 2] 16). 
gem von paläographischer Seite und glaubte, charakteristische Eigenschaften späterer Menologeme Ioannes' V. wiederzufinden, so die starke Schrägung des Anstrichs zum $\mu$, die Höherstellung der zweiten Bauchung des $\mu$ mit darin sitzendem Akzent, den eckigen Schlußschnörkel bei dem durchgezogenen $\mathbf{~}$, die starke Krümmung des Querstriches beim Indiktionszeichen und den nach abwärts gerichteten Schlußschnörkel des über diesem angebrachten $\sigma$-artigen Zeichens ${ }^{23}$. Über die Richtigkeit dieser paläographischen Beobachtungen läßt sich, wie gesehen, trefflich streiten - nicht zuletzt darüber, ob die angeführten Charakteristika nicht auch schon für die Menologemunterschriften Andronikos' III. ihre Gültigkeit haben ${ }^{24}$. Die Zuweisung des Menologems steht und fällt aber mit einer anderen Beobachtung, der Dölger selbst zu wenig Bedeutung beimaß. So wies er zwar auf den Umstand hin, daß „die Schrift (...) durch ihre Sicherheit und Zügigkeit in Erstaunen versetzt“25, zog hieraus aber nicht die notwendigen Konsequenzen. Denn gerade die Gewandtheit der Menologemunterschrift unter dem Vertrag des Jahres 1342 ist es, die sich mit einer Unterschrift durch den Knaben Ioannes V. nicht in Einklang bringen läßt.

Wir besitzen von Ioannes V. zwar keine Schriftprobe, die mit dem Menologem des Vertrages mit Venedig zeitgleich wäre, aber immerhin doch genug zeitlich benachtbartes Unterschriftsmaterial, um nachweisen zu können, daß das Menologem vom April 1342 nicht von der Hand des neunjährigen Kaisers stammen kann ${ }^{26}$. Die erste erhaltene Urkunde, die nach der Krönung des jungen Herrschers die Kaiserkanzlei verließ, ist ein Chrysobullos Logos für das Athoskloster Zographu vom Januar $1342^{27}$ (Dölger-Wirth, Regesten 2872a und 2872b) (Abb. 5). Das Privileg wurde zwei Monate vor dem Vertrag mit Venedig ausgestellt und trägt die Namensunterfertigung Ioannes' V., eine Unterzeichnung, die deutliche Anzeichen kindlicher Unbeholfenheit aufweist. So gelingt es ihr etwa nicht, beim Schreiben eine gerade horizontale Linie zu halten; die Buchstaben erscheinen insgesamt ungeübt, und auch die Schwierigkeiten, von dem noch sehr ungewohnten Schreibwerkzeug den richtigen Gebrauch zu machen, sind deutlich erkennbar. Von alledem ist bei der Menologemunterfertigung unter der $\tau \varrho \varepsilon ́ \beta \alpha$ mit Venedig nichts zu spüren. Ganz im Gegenteil: Dort ist ein kalligraphisch ausgeführter Schriftzug mit anmutigen Buchstabenformen und einer gleichmäßigen Strichführung auf das Pergament gesetzt, der eine geübte Hand erkennen läßt (vgl. nochmals Abb. 3).

Weitere Vergleichsbeispiele für frühe Unterschriften Ioannes' V. lassen sich anführen; besonders interessant ist darunter die Menologemunterschrift

23 So DölgER, Facsimiles (wie in A. 2) 17; DERS., Unterfertigung (wie in A. 3) 9, bringt demgegenüber keine neuen Beobachtungen.

${ }^{24}$ Vgl. oben, A. 13.

25 Dölger, Facsimiles (wie in A. 2) 16.

${ }_{26}$ Nur angedeutet sei, daß manche der frühen Urkundenunterschriften Ioannes' V. bei näherem Hinsehen nicht unbeträchtliche Probleme aufwerfen.

27 Actes de Zographou, publiés par W. Regel-E. Kurtz-B. Korablev (Actes de l'Athos IV = Viz. Vrem. 13, prilož. 1). St. Peterburg 1907, 72-73 (Nr. 31). - Die Urkunde ist eines jener Dokumente, die im Streit um die Mühlen von Chantax eine Rolle spielten; s. F. DöLGER, Die Mühlen von Chantax. Untersuchung über vier unechte Kaiserurkun-

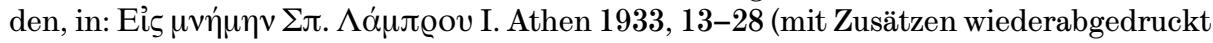
bei DEMs., Byzantinische Diplomatik. 20 Aufsätze zum Urkundenwesen der Byzantiner. Ettal 1956, 189-203) und zuletzt A. LaIou-D. Simon, Eine Geschichte von Mühlen und Mönchen. Der Fall der Mühlen von Chantax. Bullettino dell'Istituto di Diritto romano „Vittorio Scialoja“, 3. ser., 30 (1988 [ersch. 1992]) 619-676. 
unter einem Chrysobullon Sigillion vom November 1342 für die im Bereich der Stadt Serrhai angesiedelten Soldaten aus Klazomenai (Dölger-Wirth, Regesten 2883) (Abb. 4) ${ }^{28}$. Auch dieses Menologem, über ein halbes Jahr nach demjenigen des Vertrages mit Venedig ausgeführt, ist bei weitem nicht so elegant und gekonnt, wenngleich der Schriftduktus hier geübter erscheint als im Fall der Namensunterfertigung vom Januar 1342. Eine Betrachtung der Abweichungen in der Ausführung des Wortes $\mu \eta v i ́$ allerdings genügt, um zu sehen, daß die beiden Unterschriften nicht von ein und derselben Hand stammen.

Sieht man in der Unterzeichnung der Vertragsurkunde des Jahres 1342 keine autographe Subskription Ioannes' V., so beantwortet sich auch die Frage von selbst, warum hier nicht, wie üblich, mit der Namensunterschrift des Kaisers gezeichnet wurde, sondern mit dem Menologem ${ }^{29}$. Während nämlich die kaiserliche Namensunterschrift legitime von niemand anderem als dem Namensträger selbst gesetzt werden konnte, war die Unterzeichnung mit dem „anonymen“ Menologem jene Unterfertigungsart, die vom Kaiser an Drittpersonen delegiert werden konnte ${ }^{30}$.

Eine Stützung der Ansicht, daß es tatsächlich nicht der junge Kaiser war, der die Urkunde unterzeichnete, liefert dabei auch der Vertragstext selbst. Darin wird, abweichend von jeglicher Konvention, vom byzantinischen Kaiser

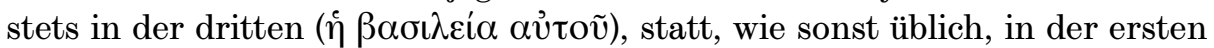

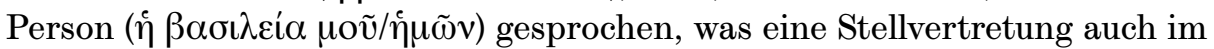
Rahmen der Unterschrift wahrscheinlich werden läßt ${ }^{31}$.

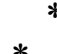

28 Actes de Kutlumus. Nouvelle édition remaniée et augmentée par P. LEMERLE ( $A r$ chives de l'Athos ${ }^{2}$ II). Paris ${ }^{2} 1988$, 90-91 (Nr. 20); ältere Edition bei F. DöLGER, Aus den Schatzkammern des Heiligen Berges. München 1948, 58 (Nr. 16).

29 Dölgers Hypothese (vgl. DERs., Unterfertigung [wie in A. 3] 8), daß Ioannes V. im März noch nicht die nötige Gewandtheit besaß, um mit der langen Namensformel zu unterzeichnen, ohne dabei einen Prestigeverlust zu riskieren, und daß er, da überdies offenbar die Zeit drängte, die kürzere Beglaubigungsformel unter den Vertrag setzten durfte, die er anscheinend leichter vollziehen konnte, ist, wie gezeigt, hinfällig. Interessant ist in diesem Zusammenhang, daß am Kaiserhof offenbar niemand auf den Gedanken kam, dem kleinen Kaiser für die Unterschrift eine Schablone zu basteln, wie dies in früheren Zeiten einmal vorgekommen sein soll: s. Procopii Caesariensis opera omnia, Bd. III: Historia, quae dicitur arcana, ed. J. HAuRY(-G. WIRTH). Leipzig 1963, 39, 19-41, 5 (VI, 10-16) zur Unterschriftsschablone für Iustinos I. Daß das Menologem unter dem Vertrag von keiner Schablone herrührt, ist deutlich zu erkennen; hätte man sich für das Basteln entschieden, so hätte man überdies wohl gleich eine Schablone gefertigt, welche die Formel für die Namensunterfertigung des Kaisers trug, wie sie der Urkundentypus des Vertrags als Unterschrift erforderlich machte.

30 Fälle von Delegierung des kaiserlichen Menologemrechts finden sich behandelt

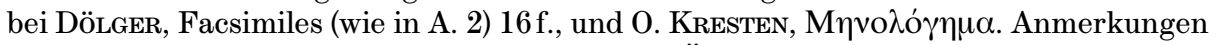
zu einem byzantinischen Unterfertigungstyp. MIÖG 102 (1994) 3-60, hier $32 \mathrm{f}$.

31 Hierbei sei nochmals erwähnt, daß der Vertragstext ausführt, die Vereinbarun-

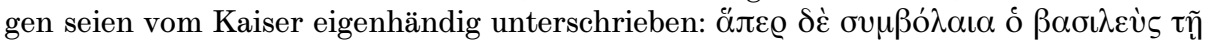

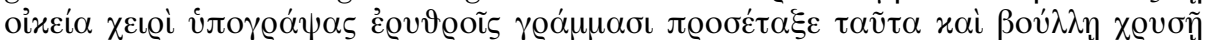
$\alpha \dot{\alpha} \varphi \alpha \lambda \tilde{\omega} \varsigma \dot{\varepsilon} \pi \iota x \cup \varrho \omega \vartheta \tilde{\eta} v \alpha-q u i b u s$ quidem instrumentis dictus dominus imperator manu propria subscripsit litteris rubeis ac iussit ipsa sue bulle auree munimine roborari (DöLGER, Facsimiles [wie in A. 2] 17, 5f.). Ein Widerspruch zu dem gerade über dem Strich Gesagten scheint mir insofern nicht zu bestehen, als solche in Vertretung geleisteten Unterschriften „rechtlich als von den jeweiligen Kaisern vollzogen anzusehen sind“ (KRE-

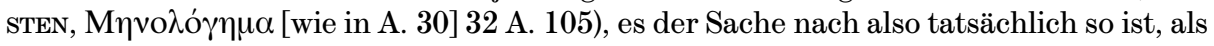
habe der Kaiser eigenhändig unterschrieben. 
Von den Personen, die neben dem Kaiser für eine Unterzeichnung der Urkunde in Frage kamen, sei zunächst Ioannes Kantakuzenos genannt ${ }^{32}$. Seine geschichtliche Rolle ist allgemein bekannt: Er war die engste Vertrauensperson Andronikos' III..$^{33}$, des Vaters Ioannes' V., und wurde von ersterem, laut seinen eigenen Aussagen, wiederholt aufgefordert, die Mitherrschaft anzunehmen, was zu tun er sich mit Rücksicht auf den legitimen Thronnachfolger standhaft weigerte ${ }^{34}$. Nach dem frühen Tod Andronikos' III., als sich die Frage nach Führung der Regentschaft für dessen minderjährigen Sohn stellte, erschien es vielen selbstverständlich, daß Ioannes Kantakuzenos, der lebenslange Freund des verstorbenen Kaisers, diese Regentschaft übernehmen sollte. Das Intrigenspiel am Hof freilich brachte die Dinge anders, und so übernahm die Kaiserin Anna ${ }^{35}$, die Gemahlin Andronikos' III. und Mutter Ioannes' V., gestützt auf den Patriarchen Ioannes XIV. Kalekas und den machtbesessenen Emporkömmling Alexios Apokaukos, die Herrschaft. Die Auseinandersetzungen zwischen dieser Partei auf der einen Seite und Ioannes Kantakuzenos und seinen Anhängern auf der anderen Seite mündeten in bürgerkriegsähnlichen Konfrontationen, welche die Geschehnisse der Jahre 1341 bis 1347 beherrschten. Ioannes Kantakuzenos selbst hatte bereits im September 1341 Konstantinopel verlassen; bei Didymoteichon in Thrakien, seinem Hauptquartier, wurde er am 16. Oktober 1341 von seinen Anhängern zum Kaiser ausgerufen. Bis er nach Konstantinopel zurückkehren konnte, sollten fünf Jahre vergehen ${ }^{36}$. Daß Ioannes Kantakuzenos den Vertrag mit Venedig unterzeichnet hätte, ist somit schon aus der skizzierten politischen Situation heraus undenkbar. Venedig hatte seinen Abgesandten, Pietro da Canali, nicht etwa zu ihm nach Didymoteichon, sondern an den Kaiserhof geschickt. Der

32 DöLGER, Facsimiles (wie in A. 2) 16; vgl. auch DERs., Unterfertigung (wie in A. 3) 7.

${ }_{33} \mathrm{Zu}$ Aufstieg und Bedeutung Ioannes Kantakuzenos' unter Andronikos III. s. jetzt Nicol, The Reluctant Emperor (wie in A. 1) 29-44; die bisherige Forschungsliteratur zu Ioannes dort S. 190-197.

${ }^{34}$ Vgl. Ioann. Kant., Hist. II 9 (Ioannis Cantacuzeni [...] Historiarum libri IV [...] cura L. SchOPEN [Corpus Scriptorum Historiae Byzantinae XX], 3 Bde., Bonn 1828-1832, hier I 364, 12 ff.) - Zur Diskussion in der Forschung, ob diese Angebote von seiten des Kaisers tatsächlich jemals erfolgten, s. Johannes Kantakuzenos, Geschichte. Übersetzt und erläutert von G. Fatouros und T. Krischer, 2. Teil (Buch II) (Bibliothek der griech. Literatur 21). Stuttgart 1986, 183, A. 74a, mit Anführung der konträren Standpunkte. Interessant ist im vorliegenden Kontext, daß Kantakuzenos selbst im Zusammenhang mit den Ausführungen über seine de facto fast kaiserlichen Rechte und Befugnisse unter Andronikos III. angibt, er habe auch Prostagmata „ebenso wie der Kaiser selbst mit roter Tinte“ unterschrieben: ع̋@

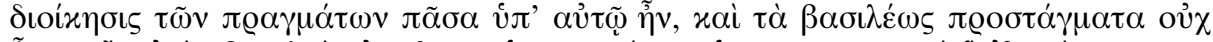

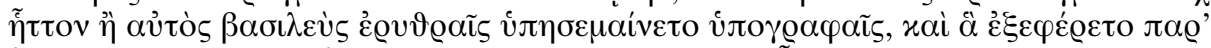

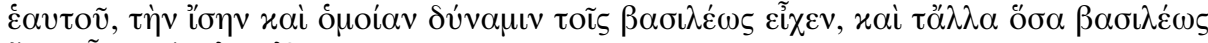

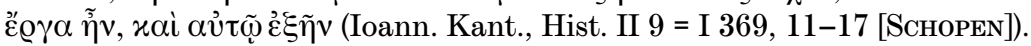

${ }_{35}$ Zur ihrer Person s. den biographischen Abriß bei D. M. NICOL, The Byzanine Lady: Ten Portraits 1250-1500. Cambridge 1994, 82-95; ausführlicher, aber in weiten Teilen veraltet ist D. MURAToRe, Una principessa Saubauda sul trono di Bisanzio. Giovanna di Savoia Imperatrice Anna Paleologina. Mémoire de l'Académie des Sciences, Belles-Lettres et Arts de Savoie, 4. ser., 11 (1909) 221-475.

${ }_{36} \mathrm{Zu}$ den politischen Ereignissen nach dem Tod Andronikos' III. s. etwa OstroGORSKY, Geschichte des byzantinischen Staates (wie in A.4) $420 \mathrm{ff}$. , und Nicol, The Reluctant Emperor (wie in A. 1) 45-83; mit den theologischen Implikationen behandelt bei H.-G. BECK, Geschichte der orthodoxen Kirche im byzantinischen Reich (Die Kirche in ihrer Geschichte I, Lieferung D 1). Göttingen 1980, $218 \mathrm{ff}$. 
Unterhändler sollte der verwitweten Kaiserin kondolieren und mit ihr die durch den Tod des Kaisers gefährdeten Verhandlungen wiederaufnehmen ${ }^{37}$. Die Seerepublik stellte sich somit eindeutig auf die Seite der Kaiserin und ihrer Partei ${ }^{38}$. Und da aus dem Vertragstext selbst hervorgeht, daß dieser in Konstantinopel im Blachernenpalast abgeschlossen wurde ${ }^{39}$, sich Kantakuzenos zum Zeitpunkt des Vertragsabschlusses jedoch nicht in Konstantinopel aufhielt, scheidet er mit letzter Sicherheit als Unterzeichner des Vertrages aus.

Wenn Ioannes Kantakuzenos als Urheber des Menologems nicht in Frage kommt, unterzeichnete dann etwa Anna den Vertrag mit Venedig ${ }^{40}$ ? Die Antwort auf diese Frage dürfte einmal mehr von paläographischer Seite kommen: Im Jahr 1984 veröffentlichte N. Oikonomides eine bis dato unedierte Urkunde des Jahres 1361 aus dem Archiv des Klosters Docheiariu ${ }^{41}$. Es handelt sich dabei um einen originalen Horismos der zu dieser Zeit in Thessalonike residierenden Kaiserin Anna ${ }^{42}$, der von ihr eigenhändig mit dem Menologem gezeichnet wurde ${ }^{43}$ (s. Abb. 7). Der Schriftduktus des in schwarzer Tinte ausgeführten Menologems ist etwas ungelenk und insgesamt wenig elegant. Zwischen dieser Unterfertigung und derjenigen unter dem Vertrag mit Venedig liegen zwar fast zwanzig Jahre, doch erscheint es abermals ausgeschlossen, daß die vorliegende Unterschrift von der gleichen Hand geleistet wurde wie die kalligraphisch gekonnte Vertragsunterzeichnung - selbst wenn man annimmt, daß man der Kaiserin im Jahr 1342 eine menologemgefertigte Urkunde ihres verstorbenen Mannes als Vorlage zur „Nachzeichnung“ vorgelegt hatte.

Damit aber reduziert sich der Kreis derer, die noch für die Unterzeichung des Vertrages mit Venedig in Frage kommen, im Grunde auf zwei Personen: den Patriarchen Ioannes XIV. Kalekas und den hohen Würdenträger Ioannes Raul. Begonnen sei mit Ioannes Raul, dem das Menologem zuzuweisen Dölger zuletzt

37 Vgl. F. Thiriet, Régestes des délibérations du sénat de Venise concernant la Romanie I (1329-1399) (Documents et recherches 1). Paris 1958, $47 \mathrm{f}$. (Nr. 132).

38 S. hierzu auch Nicol, Byzantium and Venice (wie in A. 17) $257 \mathrm{f}$.

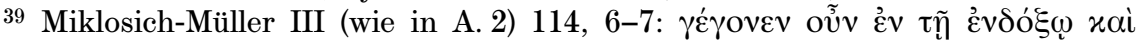

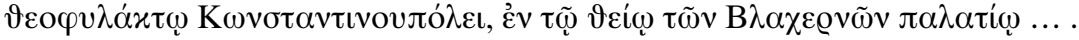

40 Dölger verneinte dies, wie gesehen, mit dem Hinweis, daß dergleichen bei der Einstellung der Byzantiner staatsrechtlichen Befugnissen der kaiserlichen Frauen gegenüber $a$ priori höchst unwahrscheinlich sei. Darüber hinaus argumentierte er, daß Anna ihre Briefe an Papst Clemens VI. vom Jahre 1345, wie Kantakuzenos mitteile, $\hat{\omega} \varsigma$ $\grave{\varepsilon} \xi$ $\alpha$ $\tau \tilde{\eta} \varsigma$ geschrieben habe; wäre sie dazu befugt gewesen, diesen Briefen mittels kaiserlichem Menologem mehr Geltung zu verschaffen, so hätte sie dies gewiß getan; s. DöLGER, Facsimiles (wie in A. 2) 16.

41 N. OIKonomidès, Actes de Docheiariou (Archives de l'Athos XIII). Paris 1984, 211-213 (Nr. 35) mit Abb. XL im „Album“.

42 Anna war im Sommer 1351 nach Thessalonike zu Verhandlungen mit ihrem Sohn Ioannes V. aufgebrochen. Sie kehrte nicht mehr nach Konstantinopel zurück, sondern blieb in Thessalonike, von wo sie in den folgenden vierzehn Jahren über ihren „Teil“ des Reiches regierte; s. hierzu Nicol, The Byzantine Lady (wie in A. 35) 92-93. Zu

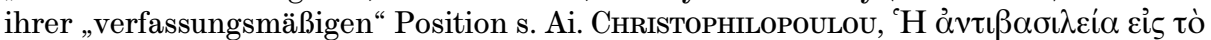

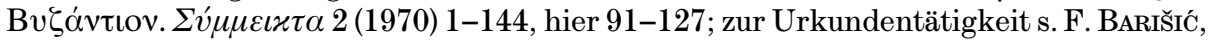
Povelje vizantijskich carica. Zbornik radova Vizantološkog Instituta 13 (1971) 143-202, hier 180-182.

43 Für die Eigenhändigkeit der Unterzeichnung spricht nicht zuletzt die von den gewöhnlichen Herrschermenologemen etwas abweichende Gestaltung der Unterschrift, die so von keinem Kanzleibeamten, hätte er in Vertretung geurkundet, ausgeführt worden wäre. S. hierzu Orkonomidès, Actes de Docheiariou (wie in A. 41) $209 \mathrm{f}$. 
geneigt war ${ }^{44}$. Dölger begründet seinen späten Meinungswandel nicht wirklich; er hält lediglich fest, die Zuweisung an den „Megas Logothetes Johannes Raul“ erscheine ihm „heute wahrscheinlicher“, nicht zuletzt, da Raul „in jener Zeit auch die Namensunterschrift des jugendlichen Kaisers beglaubigt habe“45. Abgesehen davon, daß es bedenklich erscheint, die Vermerke des Ioannes Raul, die unter manchen frühen Urkunden Ioannes' V. aufscheinen, als „Beglaubigungen “ zu bezeichnen ${ }^{46}$ und ihn dadurch als Unterschreibenden plausibel werden zu lassen, sind es auch hier wiederum gewichtige paläographische Argumente, die deutlich gegen eine Unterzeichnung durch Ioannes Raul sprechen. Betrach-

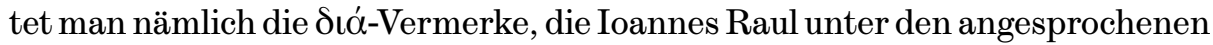
Urkunden anbrachte, so begegnet in ihnen abermals eine eher ungelenke Handschrift (s. Abb. 4 und 6), die schwer vereinbar scheint mit der Leichtigkeit und Eleganz der Unterfertigung des Vertrages mit Venedig.

Bleibt der Patriarch Ioannes Kalekas - neben der Kaiserin Anna die zentrale politische Figur der Jahre 1341 bis 1347. Im Rahmen der Regentschaft für den minderjährigen Ioannes V. spielte er eine kaum zu überschätzende Rolle, und schon allein deshalb drängt er sich bei der Frage nach den möglichen Unterzeichnern des Vertrages fast automatisch auf. Von der Warte Venedigs aus kam er nach dem jungen Kaiser wohl am ehesten für die Unterschriftsleistung in Frage, dürfte er doch, nicht zuletzt kraft seines Amtes, für die Seerepublik als der zweite Mann im Staat gegolten haben.

Über die Schriftgewandtheit des Patriarchen lassen sich heute keine Aussagen mehr treffen, da uns aus der Zeit seines Patriarchats keine Urkundenoriginale erhalten geblieben sind ${ }^{47}$, die es ermöglichen würden, die Frage nach der unterzeichnenden Person definitiv zu entscheiden. Es ist jedoch durchaus anzunehmen, daß Kalekas, der im Rahmen seines Wirkens als Patriarch seit 1334 eine Vielzahl von Dokumenten zu unterzeichnen hatte, gerade deshalb die Fähigkeit besaß, das kalligraphische Menologem unter den Vertrag mit Venedig zu setzen - umso mehr, als er gewohnt war, seine Urkunden als Patriarch von Konstantinopel nicht nur mit einer Namensformel, sondern vielfach mit einem (in schwarzer Tinte ausgeführten) Menologem (!) zu unterzeichnen.

44 Die Person des Ioannes Raul ist mangels Quellen nur schwer zu greifen; s. die Ausführungen bei S. Fassoulakis, The Byzantine Family of Raoul - Ral(l)es. Athen 1973, $46 \mathrm{f}$. (Nr. 31) und E. LAPPA-ZIZIKAS, Un chrysobulle innconu en faveur du monastère des Saint Anargyres de Kosmidion. Travaux et Mémoires 8 (1981) 255-268, hier $260 \mathrm{f}$. Eine Gleichsetzung der Person des Ioannes Raul mit Ioannes Gabalas, wie sie R.-J. LoENERTz, Dix-huit lettres de Grégoire Acindyne, analysées et datées. Orientalia Christiana Periodica 23 (1957) 128-129, vorgeschlagen hatte, erscheint heute nicht mehr wahrscheinlich.

45 DöLGER-WIRTH, Regesten (wie in A. 2) VII. - Die Bezeichnung des Ioannes Raul als „Megas Logothetes“ durch Dölger ist in diesem Zusammenhang unrichtig: Raul fir-

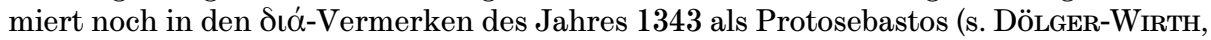
Regesten [wie in A. 2] 2887 und 2888); erst im Jahre 1344 erscheint er dort als Megas Logothetes (s. DöLGER-WIRTH, Regesten [wie in A. 2] 2899 und 2900).

46 Eine verläßliche Untersuchung zu Ursprung und Wesen der sog. ठıó-Vermerke ist immer noch ein dringendes Desiderat der Forschung, auch nach der Studie von J. KARAYANNOPULOS, Zu den „סıó-Vermerken“ der byzantinischen Kaiser, in: Documenti medievali greci e latini. Studi comparativi. Atti del seminario di Erice (23-29 ottobre 1995), a cura di G. De Gregorio-O. KRESTEN. Spoleto 1998, 203-232.

47 Dies ergibt eine Durchsicht des entsprechenden Abschnittes bei J. DARRouzÈs, Les regestes des actes du patriarcat de Constantinople I/5: Les regestes de 1310 à 1376. Paris 1977. Im April des Jahres 1342 sehen wir Ioannes Kalekas dort in Reg. 2226f. urkunden. 
Dölger meinte, den Patriarchen als Urheber des Menologems aufgrund einer Stelle im Geschichtswerk des Nikephoros Gregoras ausschließen zu müssen ${ }^{48}$. Dort heißt es zum Jahr 1344, Alexios Apokaukos habe den Patriarchen dazu aufgefordert, weder in der Kopfbedeckung noch in der Art der Urkundenunterzeichnung mehr den alten Bräuchen zu folgen, sondern vielmehr rote Schuhe anzulegen, die Kopfbedeckung mit seidenen und goldgewebten Schleiern zu schmücken und mit Hyazinthfarbe die Unterschriften seiner Briefe und Erlasse zu tätigen ${ }^{49}$. „Hätte sich der Patriarch das kaiserliche Vorrecht der Unterzeichnung mit roter Tinte schon angeeignet gehabt“, folgert Dölger, „so wäre ein solcher Vorschlag unverständlich“50. Dölger scheint hier jedoch zwei Tatbestände zu vermengen, die säuberlich getrennt sein wollen. Das, was Apokaukos dem Patriarchen schmackhaft machen will, kann man nicht anders denn als die Arrogierung des kaiserlichen Menologemrechts bezeichnen. Ioannes Kalekas solle seine eigenen Erlässe mit dem Menologem in der kaiserlichen Reservatfarbe zeichnen. Solches Tun aber hat mit den Vorgängen rund um die Unterfertigung des Vertrages mit Venedig nichts zu tun. Dort nämlich hatte der Patriarch in Stellvertretung des Kaisers einen kaiserlichen Vertrag zu unterzeichnen, wozu er im vorliegenden Fall berechtigt wurde. Es liegt also keine Arrogierung des Menologemrechts vor, sondern eine Delegierung, womit die Stelle aus Gregoras als Argument gegen die Unterfertigung durch Ioannes Kalekas ausscheidet.

Die Unterzeichnung des Vertrages durch den Patriarchen könnte schließlich auch eine Erklärung dafür bereitstellen, warum der Vertragstext mit Datum „25. März 1342“ versehen ist, während die Menologemunterschrift auf den Folgemonat April lautet: Im Jahr 1342 war die Woche um den 25. März die Karwoche ${ }^{51}$. Sollte Kalekas so mit den Vorbereitungen des Osterfestes beschäftigt gewesen sein oder eine Unterfertigung in der Karwoche für deplaziert gehalten haben und sich auf diese Weise die zeitliche Verzögerung der Unterschrift erklären lassen? Kaum mehr als eine weitere Hypothese, aber auch sie weist, wie die Mehrzahl der Argumente, die sich vorbringen lassen, auf die Person des Patriarchen als den Unterzeichner des Vertrages.

Auch wenn sich die Frage nach der unterfertigenden Hand des Vertrages von 1342 bei heutiger Quellenlage nicht mehr ganz hieb- und stichfest beweisen lassen wird, so bleibt abschließend doch festzuhalten, daß 1) Ioannes V. Palaiologos als Unterzeichner ebenso definitiv auszuschließen ist wie Ioannes Kantakuzenos und die Kaisermutter Anna und daß 2) bei der Wahl zwischen den beiden für die Unterschriftsleistung verbleibenden Personen - Ioannes

48 DöLger, Facsimiles (wie in A. 2) 16 (bei der Angabe der Quellenstelle lies 697 statt 679).

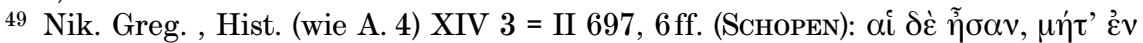

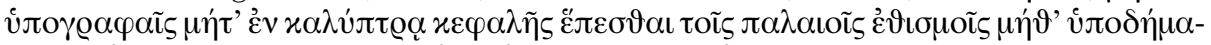

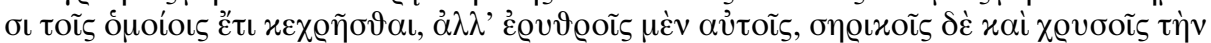

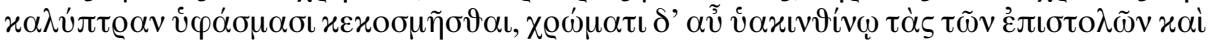

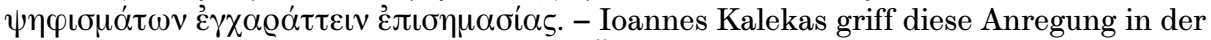
Tat auf: vgl. den Hinweis in der kopialen Überlieferung eines Dokuments des Patriarchen bei G. Mercati, Notizie di Procoro e Demetrio Cidone, Manuele Caleca e Teodoro Meliteniota ed altri appunti [...] (Studi e Testi 56). Città del Vaticano 1931, 200, 19-20.

${ }^{50}$ DöLGER, Facsimiles (wie in A. 2) 16. Vgl. auch DöLGER, Schatzkammern (wie in A. 28) $216 f$.

51 S. V. GRumel, La chronologie. Paris 1958, 261; 25. März = Montag nach Palmsonntag. 
Raul und Ioannes Kalekas - die Umstände eindeutig für die Annahme sprechen, daß es die Hand des Patriarchen war, die den Vertrag mit Venedig stellvertretend für den jungen Kaiser unterzeichnete.

\section{Abbildungsnachweis}

Alle Abbildungen entstammen dem Photoarchiv der „Kommission für die Herausgabe des Corpus der griechischen Urkunden des Mittelalters und der neueren Zeit" an der Bayerischen Akademie der Wissenschaften 
TAFEL 1

हु

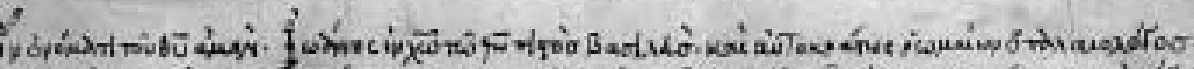

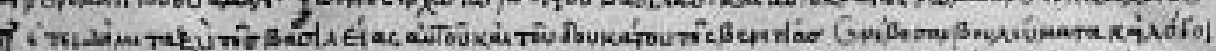

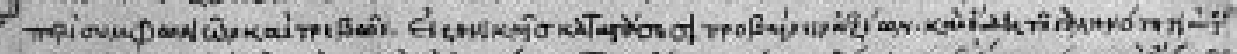
ग्रेo or

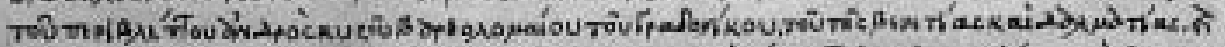

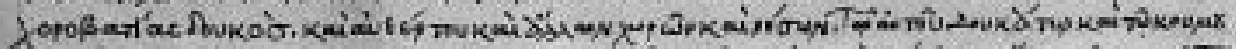

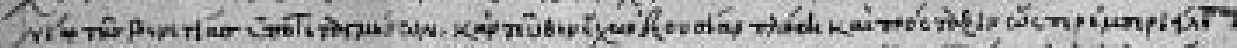

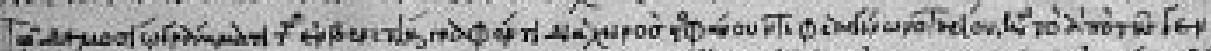

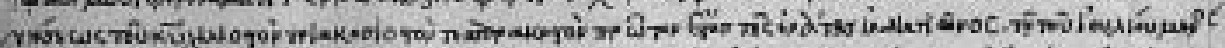

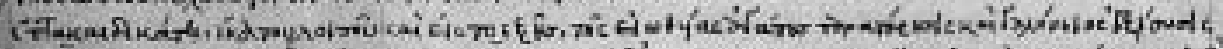

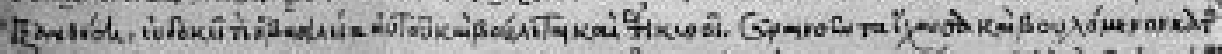

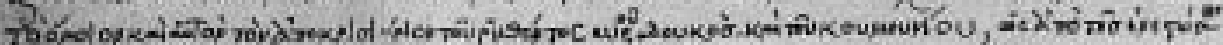

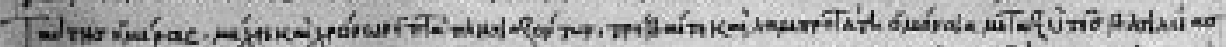

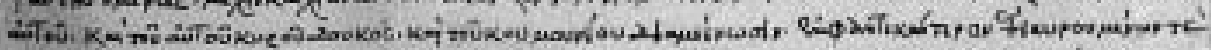

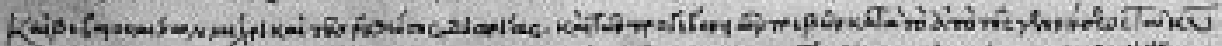

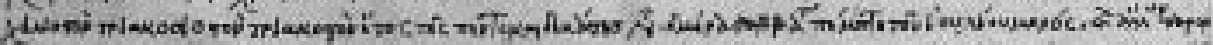

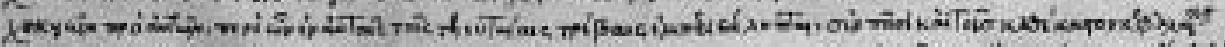

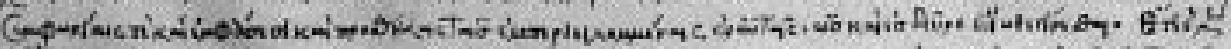

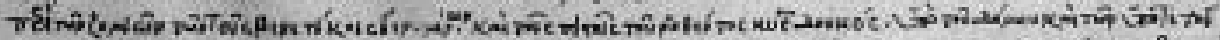

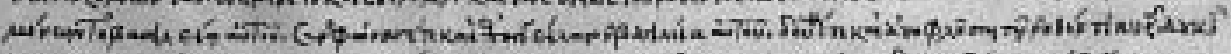

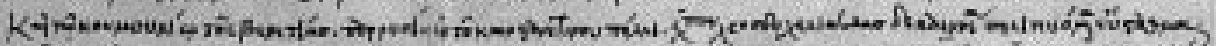

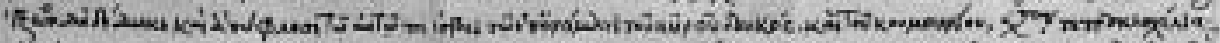

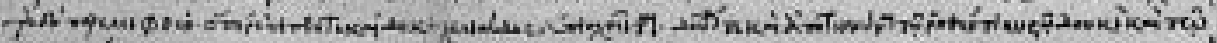

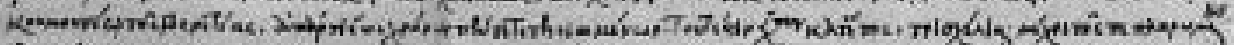

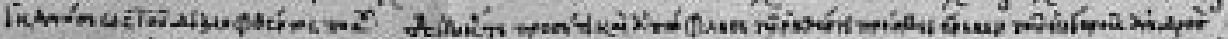

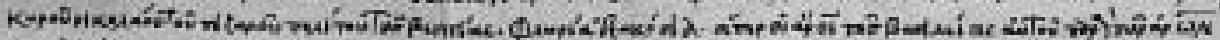

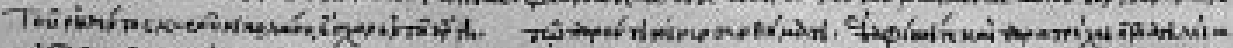

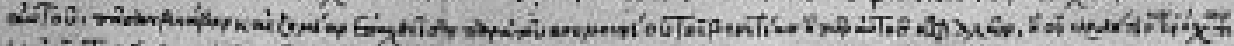

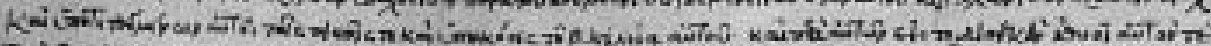

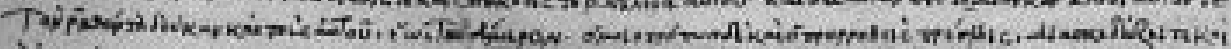

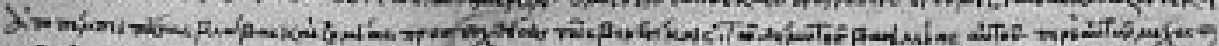

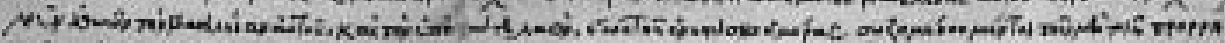

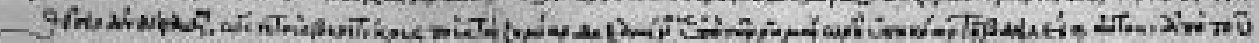

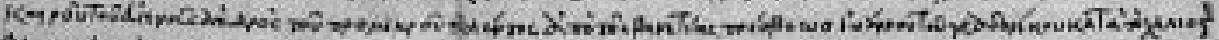

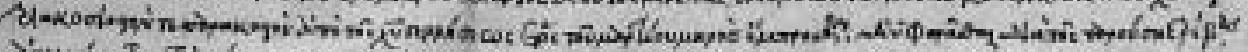

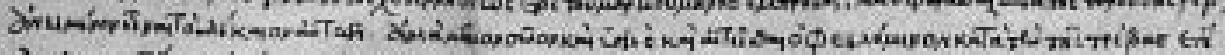

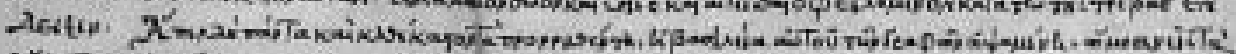

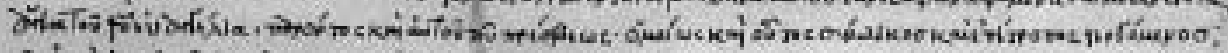

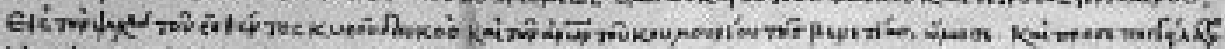

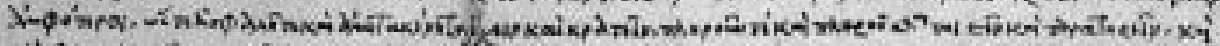

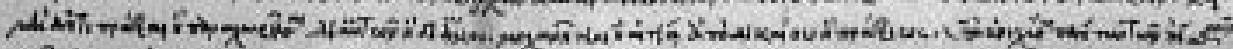

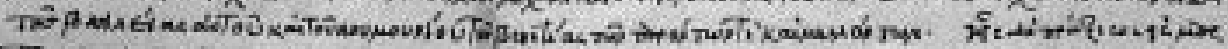

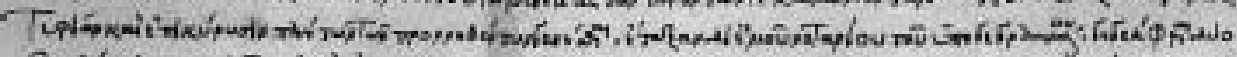

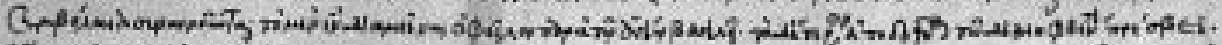

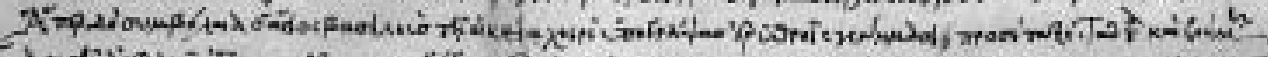

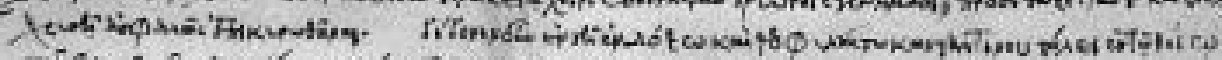
THif

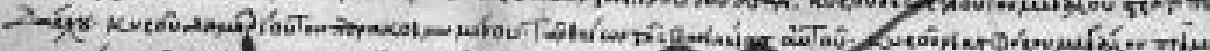

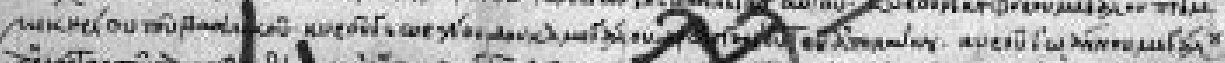

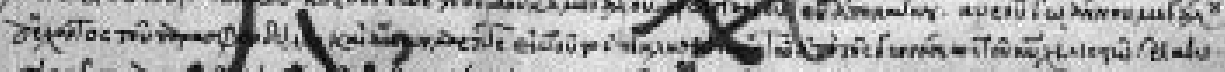

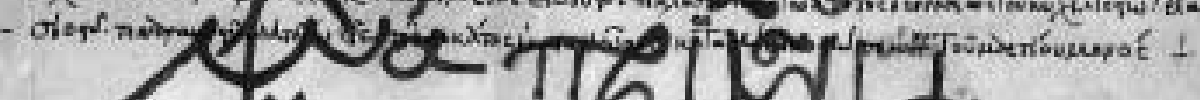

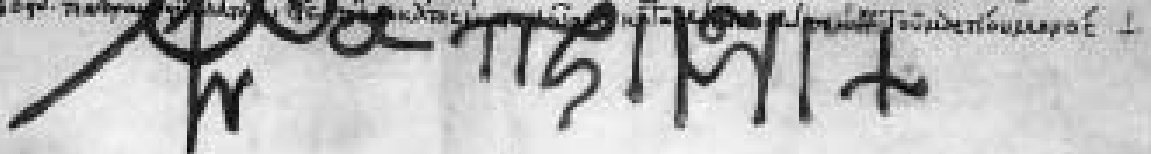

1: Vertrag zwischen Byzanz und Venedig vom 25. März 1342 (Dölger-Wirth, Regesten 2876): griechische Hälfte. 


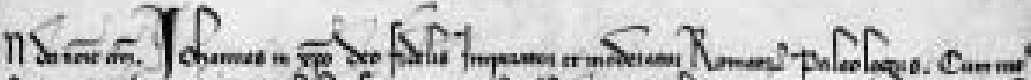

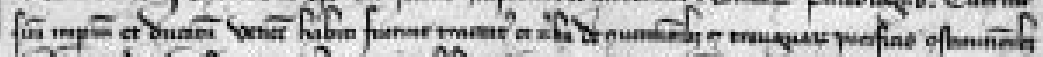

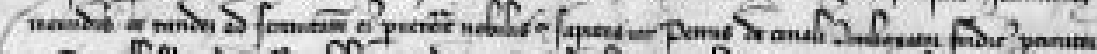

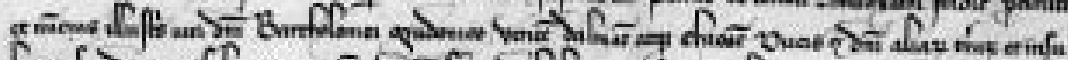

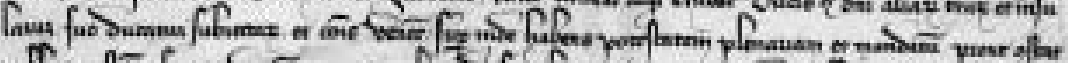

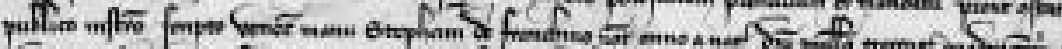

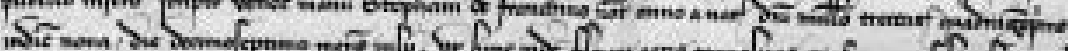
(a)

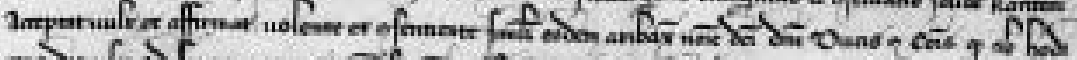

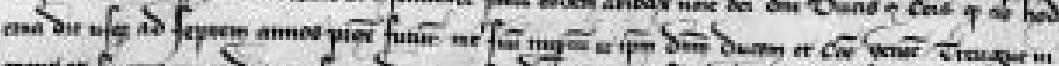

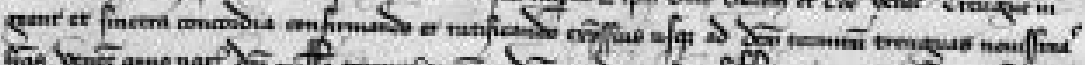

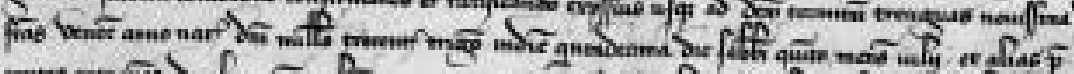

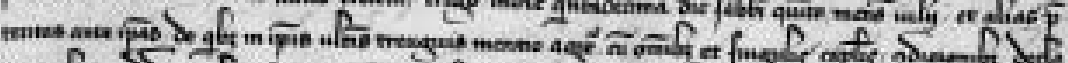

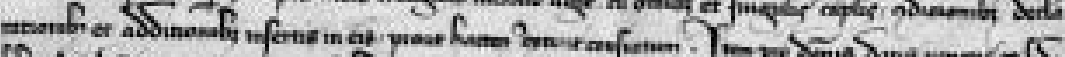

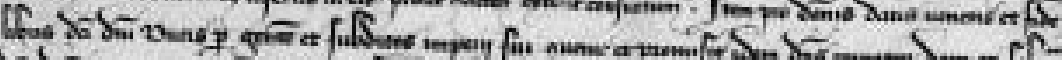

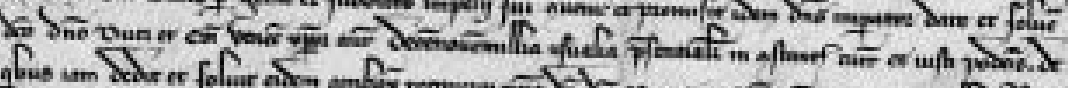

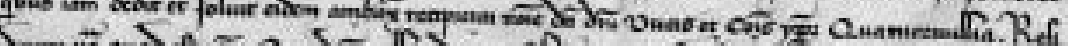

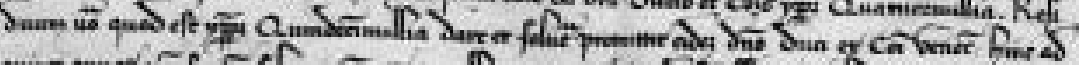

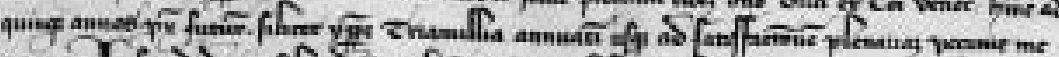

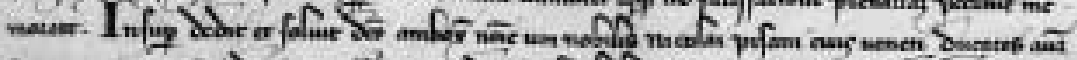

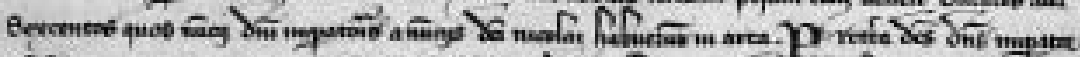

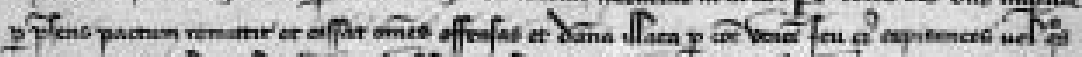

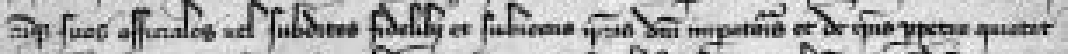

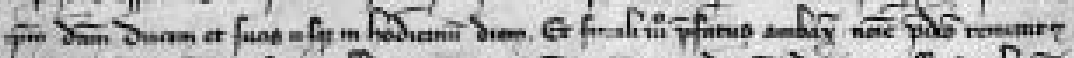

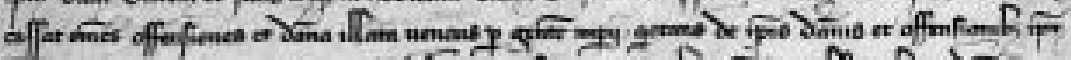

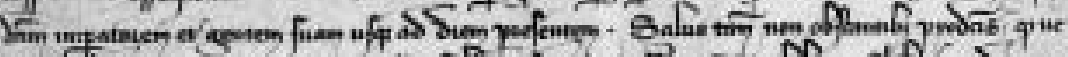

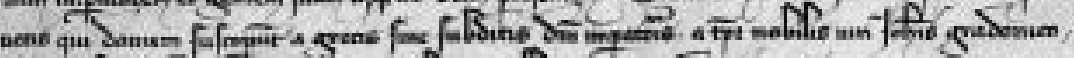

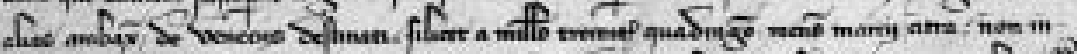

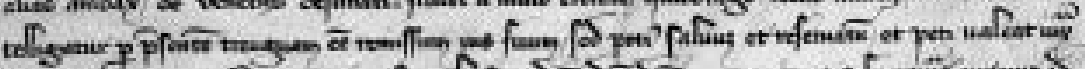

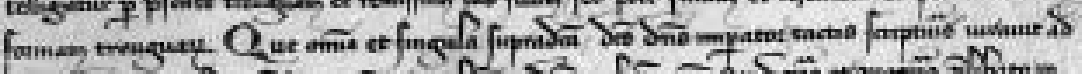

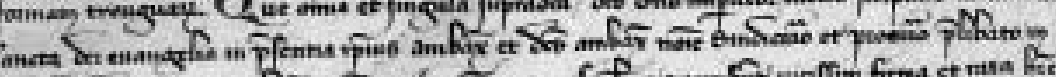

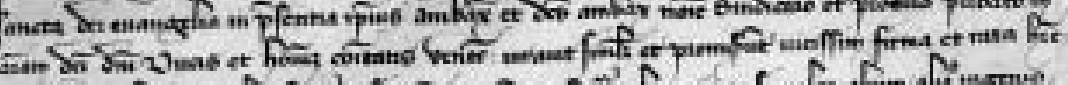

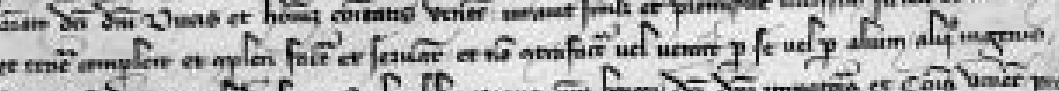

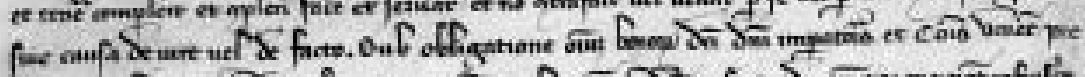

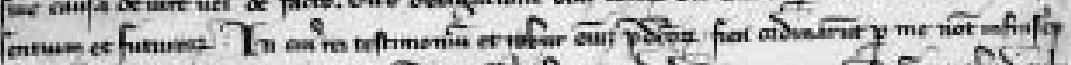

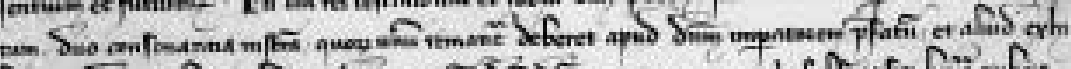

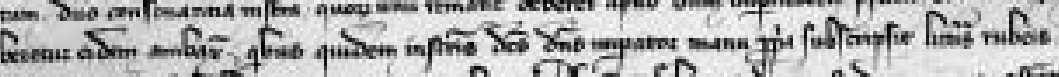

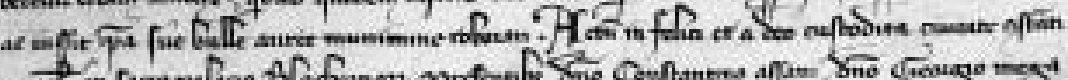

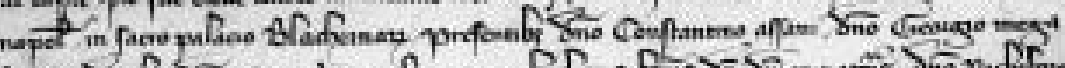

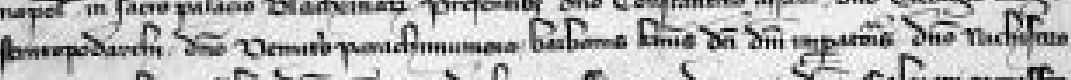

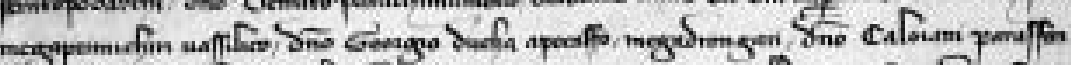

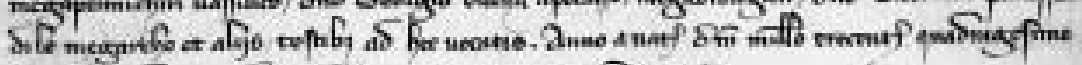

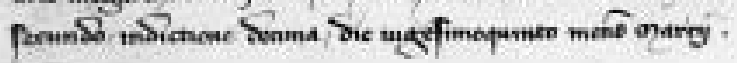

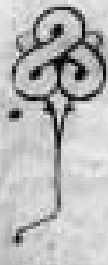

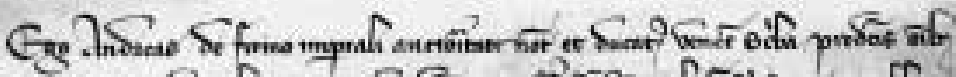

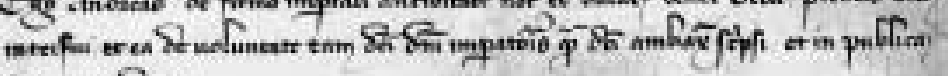
formanniog

2: Vertrag zwischen Byzanz und Venedig vom 25. März 1342 (Dölger-Wirth, Regesten 2876): lateinische Hälfte. 


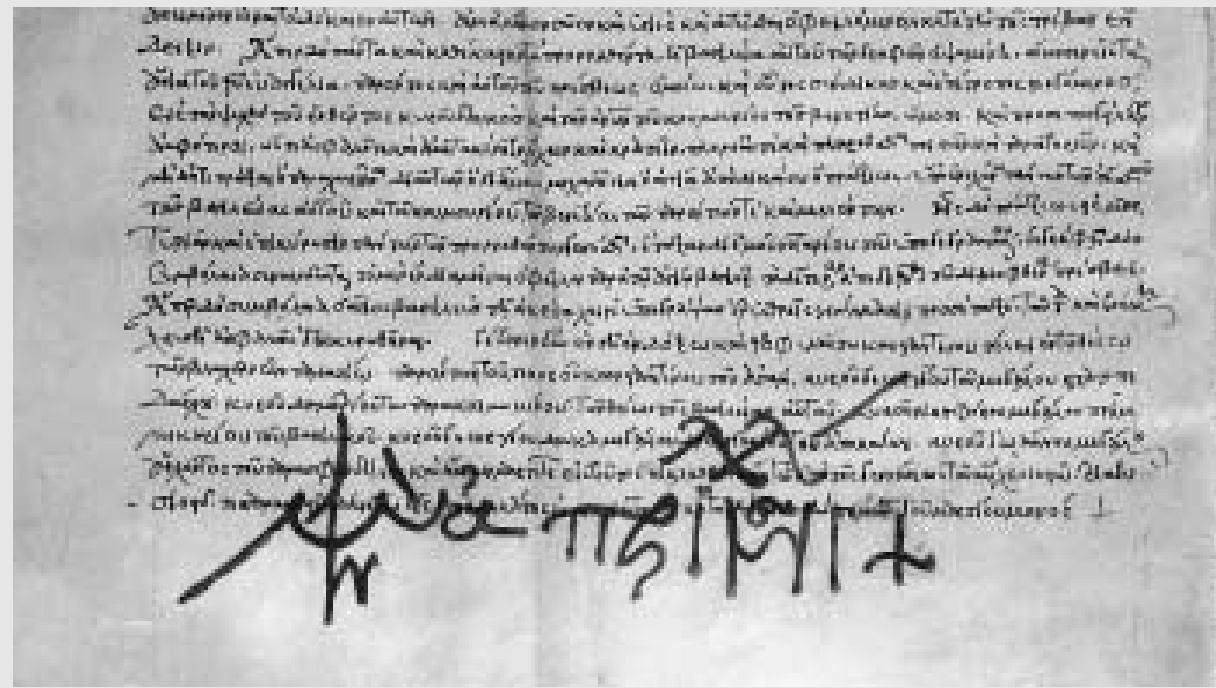

3: Vertrag zwischen Byzanz und Venedig vom 25. März 1342 (Dölger-Wirth, Regesten 2876): Menologemunterschrift.

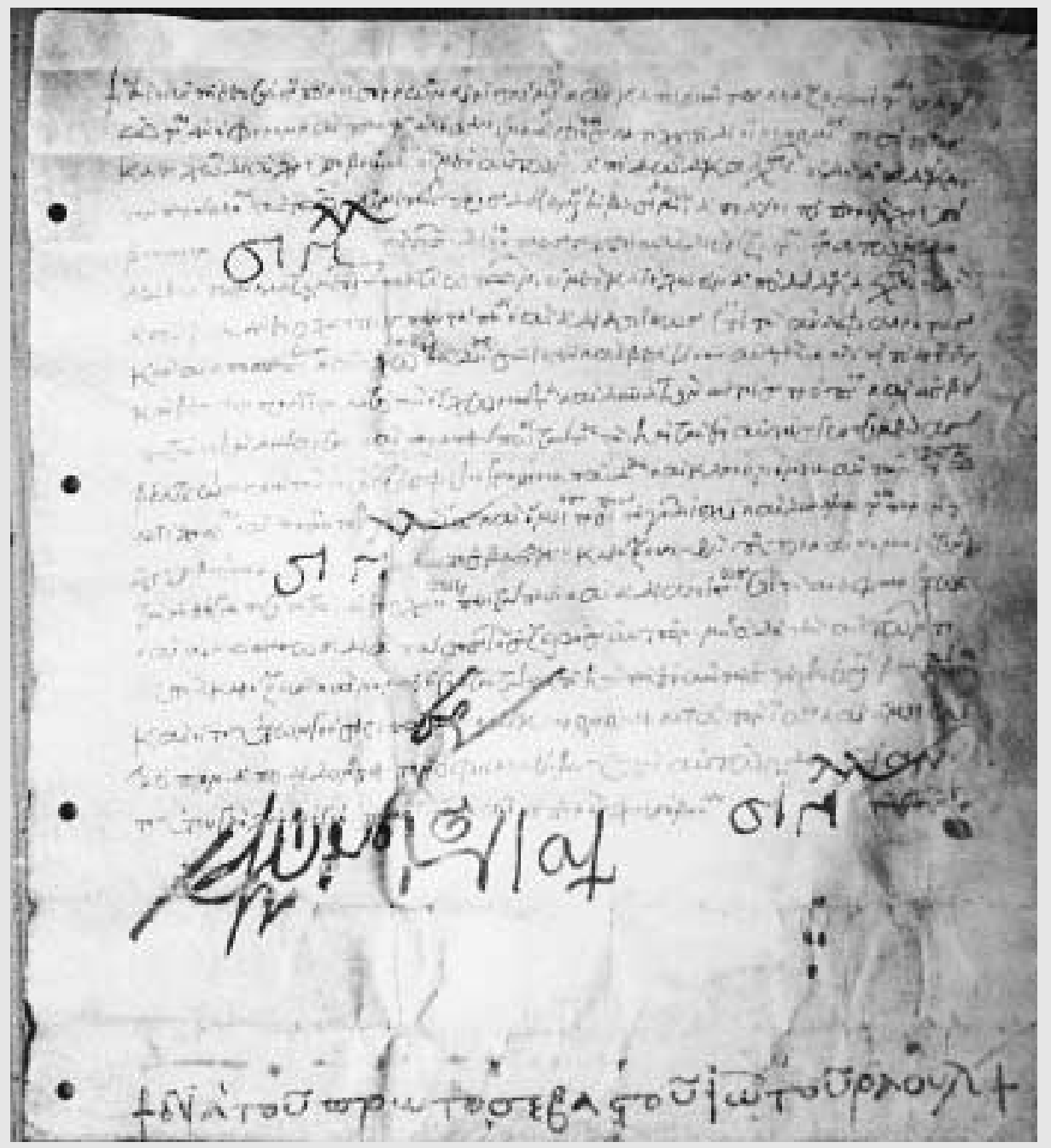

4: Chrysobullon Sigillion vom November 1342 für die im Bereich der Stadt Serrhai angesiedelten Soldaten aus Klazomenai (Dölger-Wirth, Regesten 2883): Menologemunterschrift Ioannes' V. 
TAFEL IV

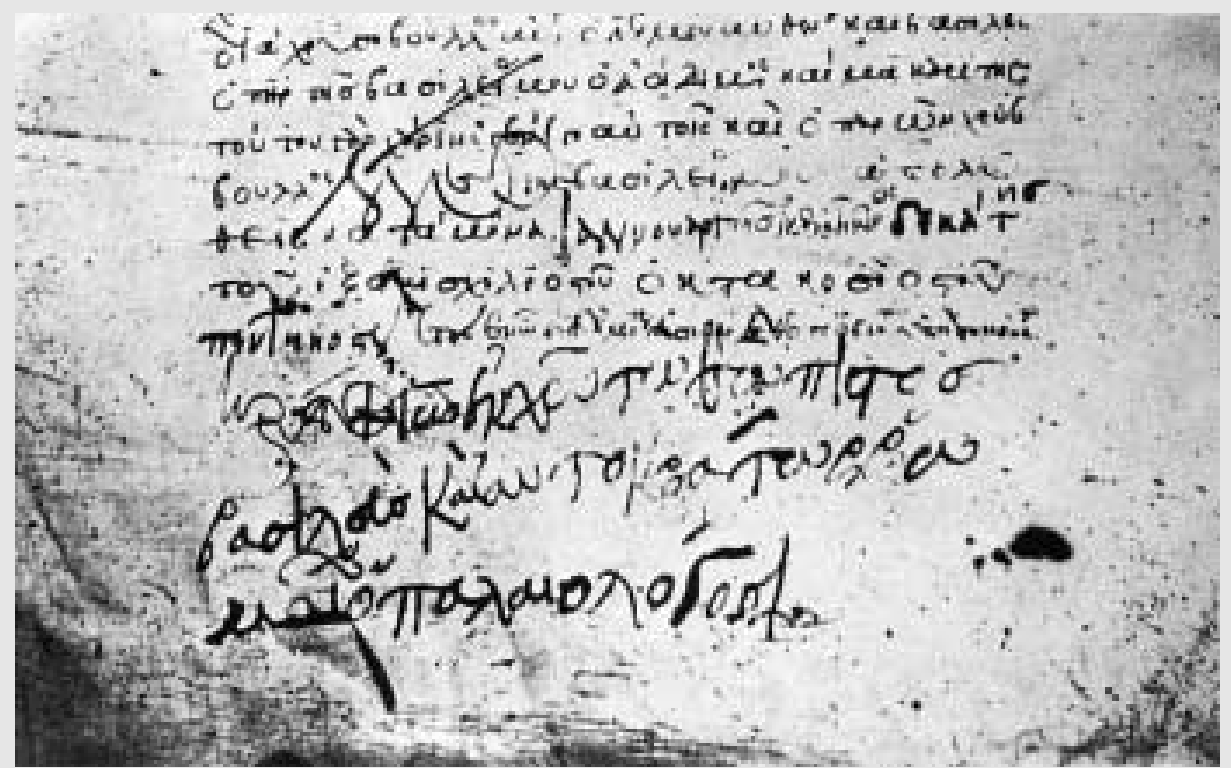

5: Chrysobullos Logos für das Athoskloster Zographu vom Januar 1342 (Dölger-Wirth, Regesten 2872a und 2872 b): Namensunterschrift Ioannes' V.

6: Chrysobullos Logos Ioannes' V. für Ioannes Chumnos vom November 1344 (Dölger-Wirth, Regesten 2900):

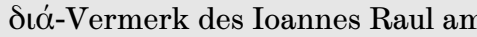
Ende der Urkunde.

7: Horismos der Kaiserin Anna vom Mai 1361 für das Kloster Docheiariu: Menologemunterschrift.
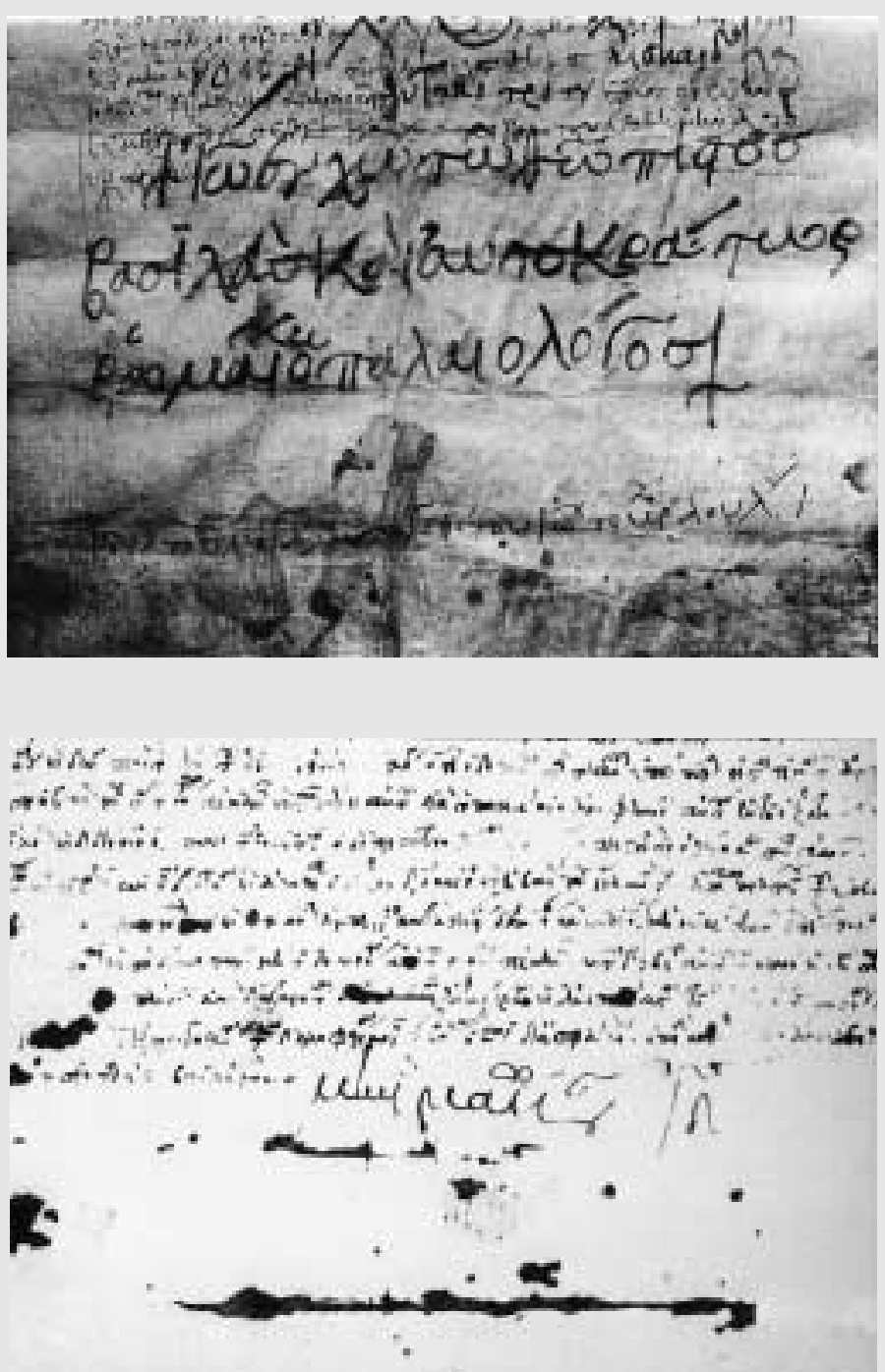
